\title{
Water Quality Assessment using the Grey Clustering Analysis on a river of Taxco, Mexico
}

\author{
Alexi Delgado ${ }^{1}$, Nicolás Rojas ${ }^{1}$, JonathanOblitas $^{1}$, Brenda Andrés $^{1}$, Araceli Huerta ${ }^{1}$, Chiara Carbajal ${ }^{2}$ \\ ${ }^{1}$ Mining Engineering Section, Pontificia Universidad Católica del Perú, Lima-Peru, kdelgadov@ pucp.edu.pe \\ ${ }^{2}$ Administration Program, Universidad de Ciencias y Humanidades, Lima-Peru, chcarbajal@uch.edu.pe
}

\begin{abstract}
Mining projects have a constant impact on the environment. One of the environmental factors that are affected is the water. Therefore, it is important to quantify how this factor has been impacted by the extraction activity. For example, the grey clustering method is an interesting alternative for evaluating some water samples, based on a variety of parameters and using artificial intelligence criteria. As a case study, the Taxco River (Mexico), which has been affected by a wastewater leak from a local mining project, will be evaluated.The objective of this study is to determine, according to the parameters established by the Peruvian Ministry of the Environment, how the river has been impacted and how efficiently the leak has been blocked. To this end, four river monitoring points were analyzed. The results showed that monitoring points 1 and 2 have a high level of contamination, even after the leak has been blocked. On the other hand, monitoring point 3 , after the leak was blocked, decreased the pollution level. While point 4 has not been affected by the leak. These results could help the company to apply some methods to purify the water in order not to affect the local population in a more centralized way. In addition, the Mexican government could use these results to control pollution caused by mining activity in the area.
\end{abstract}

Key words: Environmental impact, Grey clustering, Mining project, Water quality.

\section{INTRODUCTION}

Mining, as extractive activity, impact the environment in all its factors. One of the affected factors, specifically by generated residual water, is the water. In that sense, it is important to characterize the water and classify it to take the necessary measures to do not affect the environment nor the people living in the surroundings. This is important to mention, since it is necessary to consider that a bad water quality can bring multiples consequences such as a poor lifestyle in population health and can also affect civilization trust regarding their national authorities which can evolve in direct confrontations.
The grey clustering classification method, developed by Deng [1], can be used to make a classification through the center-point triangular whitenization weight functions (CTWF). With this methodology, it is possible to classify a group of samples into some categories. This is why this method is used in different types of applications, such as assessment of water quality [2], social impact assessment [3], [4], air quality assessment [5],etc. Therefore, in this paper, CTWF is developed as it tends to be more certain about the center-point of a grey classes compared with other points within the class [6], in that sense, conclusions based on this cognitive certainty could be more reliable.

For the case study, Taxco, Mexico, will be evaluated since is a zone where mining activities are developed. It is worth to mention that one of the mining units has had a leak of residual water on the river and the population has been affected by some residual water and, having a negative impact on the population. In this way, it is necessary to establish the degree of contamination of the river. In other words, determinate how the water of the river has been impacted by mining activities and the already mentioned accident. Which is seek through the application of a new method in Mexico (the grey clustering methodology) and that we can also use to evaluate other contaminants [7], providing as well, a comparison between the data obtained from the results during and after the accident.

The aim of this paper is to classify the water quality using the CTWF on determined samples taken in four monitoring points and analyze the results. Furthermore, the classification will be made using the Peruvian law because we want to emphasize how hard will be the process of water treatment.

The present study structure is as follows: Section 2 will detail the literature review. Section 3 describes the CTWF method. In Section 4 the case study is shown, followed by the results and discussion in Section 5. Finally, the conclusions are developed in Section 6.

\section{LITERATURE REVIEW}

Previous studies in Taxco, Mexico, which has historically been an important mining center, have determined the distribution of metals and arsenic in dissolved or particulate phase and the possible contributions along the channel with 
the purpose to help determine the possible sources of metal contamination to the Taxco River, as well as the main factors that influence its mobility [8].

Several published studies have indicated that the Taxco river water does not meet Mexican drinking water standards. For example, Armienta [9] investigated the environmental behavior of tailings metals in a branch of the Taxco River. Study in which tailings, river waters and sediments were sampled and high concentrations of $\mathrm{Pb}$ (up to $5280 \mathrm{mg} / \mathrm{kg}$ ) and $\mathrm{Zn}$ (up to $33,500 \mathrm{mg} / \mathrm{kg}$ ) in sediments were measured. The published results showed that tailings release metals because of oxidation of sulfides and erosion of rainwater. The metals are transported by the river water mainly in the form of particles and, after sedimentation, increase the concentration of metals in the sediments [9].

Likewise, the metals analyzed by Méndez and Armienta study [8] were compared with the permissible limits for drinking water established in the Official Mexican Standards NOM-001-SEMARNAT-1996 [10] and NOM-127-SSAI-1994 [11], as well as by the World Health Organization [12]. It was determined that the highest concentrations were found during the dry season. The elements that were found above the norm were $\mathrm{Fe}, \mathrm{Zn}, \mathrm{Cu}$ and $\mathrm{Cd}$, metals that tend to precipitate as carbonates or hydroxides or adsorb on solid particles in suspension, mainly iron hydroxides, and are quickly incorporated into the sediments which concentration decreases [8].

Besides this, Arcega and Cabrera study [13] to assess the mobility and possible environmental threat of $\mathrm{Pb}$ from mining waste in the sediments in a section of the Taxco River, results (geochemical fractionation and physicochemical parameters) and statistical methods were used to determine the Geochemical behavior and the real threat of $\mathrm{Pb}$ in the area. The mentioned study indicates that the main source of $\mathrm{Pb}$ for the Taxco river is anthropogenic, derived mainly from mining tailings and suggests that water from Taxco river should not be used during any of the three hydrological stations, since higher concentrations were found throughout the year, high suspended solids, which function as a shared transport vehicle for $\mathrm{Pb}$ [13].

Nevertheless, the application of Grey Clustering method in Mexico is recent, the number of articles referring to the subject are nulls; however the study carried out in March 2020 in the Gulf of Mexico to evaluate nitrogen pollution in estuaries [7] means a first approach to the methodology in this particular context. Grey Clustering use was combined with the entropy method, providing an effective tool for decision-making in the presence of limited data and opening the opportunity to develop this methodology in a country where the availability of information may be scarce.

Overall, the use of the grey clustering method is mainly due to its easy compression and programming, and its field of application can be economic evaluation[14], environmental quality[15], manufacturing [16], computing[17], and transportation[18], among others. It is important to highlight that after Deng's proposal, Liu proposed the grey fixed weight grouping evaluation model based on the center-point triangular whitenization weight function on the endpoint [19]. This allows understanding of the importance of CTWF.

To understand the methodology, it is necessary to define that a clustering is considered as a collection which belongs to the same class observation of object, and the grey clustering methodology can be then divided into the grey white weight function clustering analysis and grey cluster analysis [20]. The use of these divisions allows to analyze the established categories and to provide an adequate treatment, as well as to simplify complex systems if exists, facilitating the gathering of clustering information.

\section{METHODOLOGY}

In this section of the paper, the methodology to be used and the steps to follow will be detailed.

To begin with, the CTWF method can make a classification called Grey Clustering[1] using a set of $n$ water quality parameters, a set of $k$ grey classes or categories, and a set of monitoring values $x_{j}^{i}(i=1,2, \ldots, m ; j=1,2, \ldots, n)$ [3], [6]. To do this classification, the steps described below must be performed:

\subsection{First Step}

Once the monitoring data $(i)$ and standard values for each water quality parameter $(j)$ are obtained, the non-dimension of both is performed.

\subsection{Second Step}

Using the CTWF method, the functions $\left(f_{j}^{k}\right)$ are calculated to classify each sample by the three Peruvian water quality categories $(k)$ based in each parameter selected $(j)$ as shown in Figure 1.

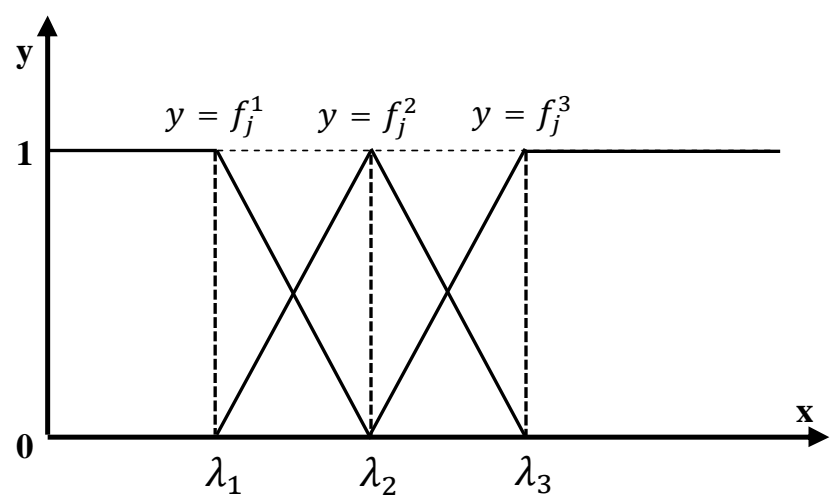

Figure 1: CTWF representation [2]

Where:

$y=f_{j}^{1}=A_{1}$ : Water might be purified by disinfection.

$y=f_{j}^{2}=A_{2}$ : Water might be purified by conventional treatment.

$y=f_{j}^{3}=A_{3}$ : Water might be purified by advanced treatment.

Then, CTWF will be calculated from the $k^{\text {th }}$ Grey class ( $k=$ $1,2 \ldots m)$, of the $j^{t h}$ parameter $(j=1,2 \ldots n)$, for a value of the monitoring of the water quality $x_{j}^{i}$ using (1) - (3)[2]. 


$$
\begin{aligned}
& f_{j}^{1}\left(x_{i j}\right)=\left\{\begin{array}{c}
1, x \in\left[0, \lambda_{j}^{1}\right] \\
\frac{\lambda_{j}^{2}-x}{\lambda_{j}^{2}-\lambda_{j}^{1}}, x \in\left\langle\lambda_{j}^{1}, \lambda_{j}^{2}\right\rangle \\
0, x \in\left[\lambda_{j}^{2},+\infty\right\rangle
\end{array}\right. \\
& f_{j}^{2}\left(x_{i j}\right)=\left\{\begin{array}{c}
\frac{x-\lambda_{j}^{1}}{\lambda_{j}^{2}-\lambda_{j}^{1}}, x \in\left\langle\lambda_{j}^{1}, \lambda_{j}^{2}\right] \\
\frac{\lambda_{j}^{3}-x}{\lambda_{j}^{3}-\lambda_{j}^{2}}, x \in\left\langle\lambda_{j}^{1}, \lambda_{j}^{2}\right\rangle \\
0, x \in\left[0, \lambda_{j}^{1}\right] \cup\left[\lambda_{j}^{3},+\infty\right\rangle
\end{array}\right. \\
& f_{j}^{3}\left(x_{i j}\right)=\left\{\begin{array}{c}
\frac{x-\lambda_{j}^{2}}{\lambda_{j}^{3}-\lambda_{j}^{2}}, x \in\left\langle\lambda_{j}^{2}, \lambda_{j}^{3}\right\rangle \\
1, x \in\left[\lambda_{j}^{3},+\infty\right\rangle
\end{array}\right. \\
& 0, x \in\left[0, \lambda_{j}^{2}\right]
\end{aligned}
$$

\subsection{Third Step}

Considering the problem of subjectivity in the traditional grey clustering evaluation method [21] the weight $\left(n_{j}\right)$ for each parameter will be determined using the harmonic mean by (4).

$$
\eta_{j}^{k}=\frac{1 / \lambda_{j}^{k}}{\sum_{j=1}^{m} 1 / \lambda_{j}^{k}}
$$

\subsection{Fourth Step}

After the weights $\left(n_{j}\right)$ for each parameter is calculated, the next step is to obtain the compressive clustering coefficient for each monitoring point $i$, with respect to the grey class $k$ using (5).

$$
\sigma_{i}^{k}=\sum_{j=1}^{n} f_{j}^{k}\left(x_{i j}\right) \cdot \eta_{j}
$$

\subsection{Fifth Step}

Finally, the grey class $(k)$ for each sample $(i)$ is decided by using the $\max \left(\sigma_{j}^{k}\right)$ for each sample. It represents that the clustering object belongs to grey classification $k$. In row vector $\sigma_{i}=\left(\sigma_{i}^{1}, \sigma_{i}^{2}, \ldots \sigma_{i}^{k}\right)$, the grey classification corresponding with the maximum clustering coefficient will be assumed as the rank of water quality [22].

\section{CASE STUDY}

This paper will be developed to evaluate the grade of contamination in a river near mining units in Taxco, Mexico. It is located in the Sierra Madre del Sur Province, sub-province 67 in the Balsas Depression, with a topoform system of mountain ranges and gullies [8].

Taxco is part of The Taxco Volcanic Field (TVF), a broad magmatic province in southern Mexico that constitutes an isolated zone of deeply dissected volcanic rocks encircled by outcrops of Mesozoic sedimentary and volcano-sedimentary units [23]. Mineralization appearsmainly in hydrothermal veins, replacement minerals, reserves of limestone, calcareous schist, and shale.

The principal sulfide minerals in the area are pyrite (which has a presence rank up to $10 \%$ to $15 \%$ ), sphalerite (11\%), and galena (4\%). Among the main gangue minerals are quartz, calcite, and feldspar. Other primary sulfide minerals in veins throughout the Taxco area are chalcopyrite, argentite, pirargite, proustite, and arsenopyrite [24].

Taxco River is between the Mexcala Formation and the Morelos formation. The first one is characterized by the presence of shale, limonite, sandstone and a limestone conglomerate of marine origin that correspond to the Upper Cretaceous. Meanwhile, Morelos Formation is mainly composed of platform limestone with some dolomitized horizons that belongs to the Lower Cretaceous [8].

Taxco River receives mine waste from several piles of tailings along its flow. In addition, Taxco river also receives untreated urban wastewater discharged from the city itself (approximately 50,000 m3d-1)[13].

The concentration levels of $\mathrm{Pb}, \mathrm{As}, \mathrm{Zn}$ and $\mathrm{Fe}$ and location of tailings represent an important environmental hazard. Release and transport to the river, mainly in the form of particulates, is mobilizing metals and metalloids in Taxco river area. Dissolution processes in the water sediment interphase may release metals to the river-water and increase the water pollution and the environmental dispersion of metals [9].The samples of this data have been taken during and after a residual water leak. In conjunction with this data, is sought to determinate if the leak has been locked successfully by the mining company when it handled the situation.

The standard values of each parameter have been taken from the Peruvian law, established by MINAM [25]. The reason of this decision is that we would like to classify this water by the level of the process that it would be necessary to purify the water which is the main objective of the mentioned law.

\subsection{Samples and Parameters}

The samples of the data have been taken in four points of the river. The same points have been taken during the leak and after locked it. The numeration of the samples considerate how close is the sample of the mining unit. The dispersion of points is shown in Figure 2.

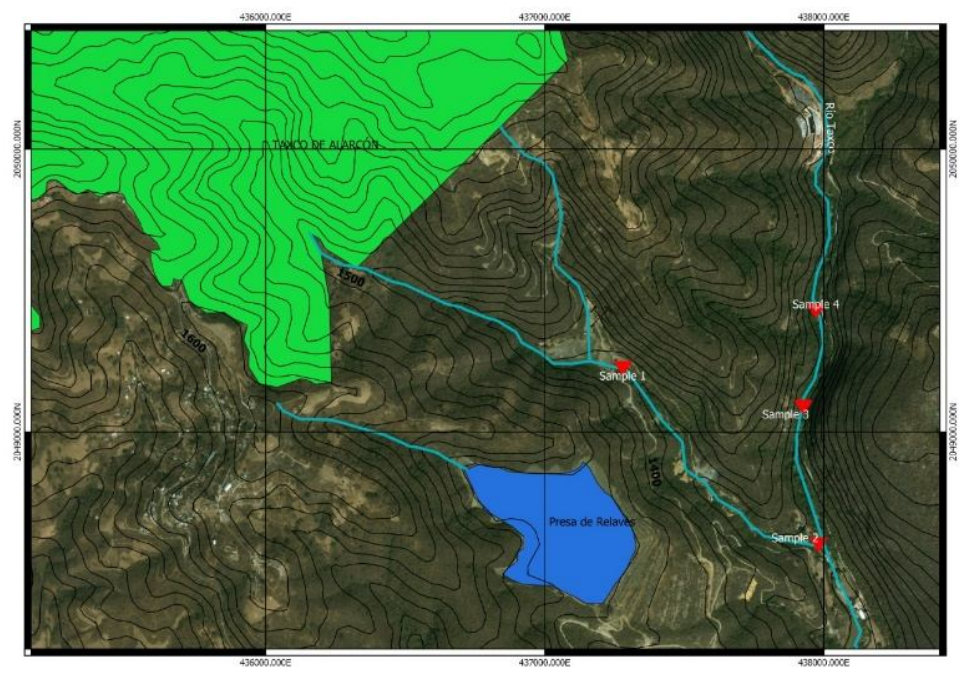

Figure 2: Monitoring Points Distribution 
Therefore, the monitoring data from the sample points resulting from the leak and after it was locked are shown in Table 1 and Table 2 respectively.

Table 1: Monitoring data resulting from the leak

\begin{tabular}{|l|c|c|c|c|c|}
\hline Code & Parameters & $\boldsymbol{S}_{\mathbf{1}}$ & $\boldsymbol{S}_{\mathbf{2}}$ & $\boldsymbol{S}_{\mathbf{3}}$ & $\boldsymbol{S}_{\mathbf{4}}$ \\
\hline $\boldsymbol{C}_{\mathbf{1}}$ & $\mathbf{A l}$ & 160.50 & 69.90 & 0.25 & 0.11 \\
\hline $\boldsymbol{C}_{\mathbf{2}}$ & $\mathbf{A s}$ & 0.10 & 0.05 & 0.02 & 0.02 \\
\hline $\boldsymbol{C}_{\mathbf{3}}$ & $\mathbf{C d}$ & 5.44 & 3.48 & 0.32 & 0.09 \\
\hline $\boldsymbol{C}_{\mathbf{4}}$ & $\mathbf{C u}$ & 11.57 & 3.38 & 0.05 & 0.02 \\
\hline $\boldsymbol{C}_{\mathbf{5}}$ & $\mathbf{F e}$ & 545.70 & 94.80 & 0.39 & 0.25 \\
\hline $\boldsymbol{C}_{\mathbf{6}}$ & $\mathbf{M n}$ & 130.50 & 58.20 & 5.94 & 1.79 \\
\hline $\boldsymbol{C}_{\mathbf{7}}$ & $\mathbf{P b}$ & 0.11 & 0.06 & 0.03 & 0.03 \\
\hline $\boldsymbol{C}_{\mathbf{8}}$ & $\mathbf{Z n}$ & 937.20 & 599.40 & 49.63 & 11.23 \\
\hline
\end{tabular}

Table 2: Monitoring data resulting after the leak

\begin{tabular}{|c|c|c|c|c|c|}
\hline Code & Parameters & $\boldsymbol{S}_{\mathbf{1}}$ & $\boldsymbol{S}_{\mathbf{2}}$ & $\boldsymbol{S}_{\mathbf{3}}$ & $\boldsymbol{S}_{\mathbf{4}}$ \\
\hline $\boldsymbol{C}_{\mathbf{1}}$ & $\mathbf{A l}$ & 147.98 & 36.98 & 0.42 & 0.14 \\
\hline $\boldsymbol{C}_{\mathbf{2}}$ & $\mathbf{A s}$ & 0.17 & 0.05 & 0.00 & 0.02 \\
\hline $\boldsymbol{C}_{\mathbf{3}}$ & $\mathbf{C d}$ & 4.79 & 2.28 & 0.05 & 0.03 \\
\hline $\boldsymbol{C}_{\mathbf{4}}$ & $\mathbf{C u}$ & 12.86 & 1.96 & 0.04 & 0.04 \\
\hline $\boldsymbol{C}_{\mathbf{5}}$ & $\mathbf{F e}$ & 462.94 & 46.90 & 0.44 & 0.18 \\
\hline $\boldsymbol{C}_{\boldsymbol{6}}$ & $\mathbf{M n}$ & 122.89 & 41.41 & 1.66 & 1.00 \\
\hline $\boldsymbol{C}_{\mathbf{7}}$ & $\mathbf{P b}$ & 0.21 & 0.08 & 0.00 & 0.03 \\
\hline $\boldsymbol{C}_{\mathbf{8}}$ & $\mathbf{Z n}$ & 873.00 & 418.56 & 5.02 & 0.66 \\
\hline
\end{tabular}

The values of the standard parameters given by MINAM [25] have been adjusted using the average. The result of that operation is shown in Table 3.

Table 3: Standard Values Average

\begin{tabular}{|l|c|c|c|c|}
\hline \multirow{2}{*}{ Code } & \multirow{2}{*}{ Parameter } & \multicolumn{3}{|c|}{ Class } \\
\cline { 3 - 5 } & & $\boldsymbol{A}_{\mathbf{1}}$ & $\boldsymbol{A}_{\mathbf{2}}$ & $\boldsymbol{A}_{\mathbf{3}}$ \\
\hline $\boldsymbol{C}_{\mathbf{1}}$ & $\mathbf{A l}$ & 0.9 & 2.95 & 5 \\
\hline $\boldsymbol{C}_{\mathbf{2}}$ & $\mathbf{A s}$ & 0.01 & 0.08 & 0.15 \\
\hline $\boldsymbol{C}_{\mathbf{3}}$ & $\mathbf{C d}$ & 0.003 & 0.005 & 0.01 \\
\hline $\boldsymbol{C}_{\mathbf{4}}$ & $\mathbf{C u}$ & 1 & 2 & 3 \\
\hline $\boldsymbol{C}_{\mathbf{5}}$ & $\mathbf{F e}$ & 0.3 & 1 & 5 \\
\hline $\boldsymbol{C}_{\mathbf{6}}$ & $\mathbf{M n}$ & 0.3 & 0.4 & 0.5 \\
\hline $\boldsymbol{C}_{\mathbf{7}}$ & $\mathbf{P b}$ & 0.01 & 0.03 & 0.05 \\
\hline $\boldsymbol{C}_{\mathbf{8}}$ & $\mathbf{Z n}$ & 3 & 4 & 5 \\
\hline
\end{tabular}

\subsection{CTWF Methodology Application}

\section{A. First Step}

The non-dimension of the standard values is performed, the results are shown in Table 4.
Table 4: Non-dimensioned Standard Values

\begin{tabular}{|l|c|c|c|c|}
\hline \multirow{2}{*}{ Code } & \multirow{2}{*}{ Parameter } & \multicolumn{3}{|c|}{ Class } \\
\cline { 3 - 5 } & & $\boldsymbol{A}_{\mathbf{1}}$ & $\boldsymbol{A}_{\mathbf{2}}$ & $\boldsymbol{A}_{\mathbf{3}}$ \\
\hline $\boldsymbol{C}_{\boldsymbol{1}}$ & $\mathbf{A l}$ & 0.305 & 1.000 & 1.695 \\
\hline $\boldsymbol{C}_{\mathbf{2}}$ & $\mathbf{A s}$ & 0.125 & 1.000 & 1.875 \\
\hline $\boldsymbol{C}_{\mathbf{3}}$ & $\mathbf{C d}$ & 0.500 & 0.833 & 1.667 \\
\hline $\boldsymbol{C}_{\mathbf{4}}$ & $\mathbf{C u}$ & 0.500 & 1.000 & 1.500 \\
\hline $\boldsymbol{C}_{\mathbf{5}}$ & $\mathbf{F e}$ & 0.143 & 0.476 & 2.381 \\
\hline $\boldsymbol{C}_{\mathbf{6}}$ & $\mathbf{M n}$ & 0.750 & 1.000 & 1.250 \\
\hline $\boldsymbol{C}_{\mathbf{7}}$ & $\mathbf{P b}$ & 0.333 & 1.000 & 1.667 \\
\hline $\boldsymbol{C}_{\mathbf{8}}$ & $\mathbf{Z n}$ & 0.750 & 1.000 & 1.250 \\
\hline
\end{tabular}

The same non-dimension operation is performed with the monitoring data of the samples. The results are presented on Tables 5 and 6.

Table 5: Non-dimensioned monitoring data resulting from the leak

\begin{tabular}{|c|c|c|c|c|c|}
\hline Code & Parameters & $\boldsymbol{S}_{\mathbf{1}}$ & $\boldsymbol{S}_{\mathbf{2}}$ & $\boldsymbol{S}_{\mathbf{3}}$ & $\boldsymbol{S}_{\mathbf{4}}$ \\
\hline $\boldsymbol{C}_{\mathbf{1}}$ & $\mathbf{A l}$ & 54.41 & 23.69 & 0.08 & 0.04 \\
\hline $\boldsymbol{C}_{\mathbf{2}}$ & $\mathbf{A s}$ & 1.23 & 0.68 & 0.25 & 0.25 \\
\hline $\boldsymbol{C}_{\mathbf{3}}$ & $\mathbf{C d}$ & 906.00 & 579.67 & 54.00 & 15.42 \\
\hline $\boldsymbol{C}_{\mathbf{4}}$ & $\mathbf{C u}$ & 5.79 & 1.69 & 0.03 & 0.01 \\
\hline $\boldsymbol{C}_{\mathbf{5}}$ & $\mathbf{F e}$ & 259.86 & 45.14 & 0.19 & 0.12 \\
\hline $\boldsymbol{C}_{\mathbf{6}}$ & $\mathbf{M n}$ & 326.25 & 145.50 & 14.85 & 4.48 \\
\hline $\boldsymbol{C}_{\mathbf{7}}$ & $\mathbf{P b}$ & 3.60 & 1.87 & 1.00 & 1.00 \\
\hline $\boldsymbol{C}_{\mathbf{8}}$ & $\mathbf{Z n}$ & 234.30 & 149.85 & 12.41 & 2.81 \\
\hline
\end{tabular}

Table 6: Non-dimensioned monitoring data resulting after the leak

\begin{tabular}{|c|c|c|c|c|c|}
\hline Code & Parameters & $\boldsymbol{S}_{\mathbf{1}}$ & $\boldsymbol{S}_{\mathbf{2}}$ & $\boldsymbol{S}_{\mathbf{3}}$ & $\boldsymbol{S}_{\mathbf{4}}$ \\
\hline $\boldsymbol{C}_{\boldsymbol{1}}$ & $\mathbf{A l}$ & 50.16 & 12.54 & 0.14 & 0.05 \\
\hline $\boldsymbol{C}_{\boldsymbol{2}}$ & $\mathbf{A s}$ & 2.14 & 0.63 & 0.00 & 0.25 \\
\hline $\boldsymbol{C}_{\boldsymbol{3}}$ & $\mathbf{C d}$ & 798.78 & 379.17 & 8.68 & 4.17 \\
\hline $\boldsymbol{C}_{\mathbf{4}}$ & $\mathbf{C u}$ & 6.43 & 0.98 & 0.02 & 0.02 \\
\hline $\boldsymbol{C}_{\mathbf{5}}$ & $\mathbf{F e}$ & 220.45 & 22.33 & 0.21 & 0.08 \\
\hline $\boldsymbol{C}_{\mathbf{6}}$ & $\mathbf{M n}$ & 307.21 & 103.53 & 4.15 & 2.50 \\
\hline $\boldsymbol{C}_{\mathbf{7}}$ & $\mathbf{P b}$ & 6.87 & 2.65 & 0.00 & 1.00 \\
\hline $\boldsymbol{C}_{\mathbf{8}}$ & $\mathbf{Z n}$ & 218.25 & 104.64 & 1.25 & 0.16 \\
\hline
\end{tabular}

\section{B. Second Step}

To obtain the CTWF in the three Grey classification, the values of the Table 4 were replaced as shown in (6) - (8) (for which the functions of the parameter $\mathrm{C} 1$ are considered as an example).

$$
\begin{gathered}
f_{j}^{1}(x)=\left\{\begin{array}{c}
0, x \notin[0,1] \\
1, x \in\langle 0,0.305\rangle \\
\frac{1-\mathrm{x}}{1-0.305}, x \in[0.305,1\rangle
\end{array}\right. \\
f_{j}^{2}(\mathrm{x})=\left\{\begin{array}{cc}
0, x \notin\langle 0.305,1.695] \\
\frac{\mathrm{x}-0.305}{1-0.305}, x \in\langle 0.305,1\rangle \\
\frac{1.695-\mathrm{x}}{1.695-1}, x \in[1,1.695\rangle
\end{array}\right.
\end{gathered}
$$




$$
f_{j}^{3}(\mathrm{x})=\left\{\begin{array}{c}
0, x \notin[1, \infty] \\
\frac{\mathrm{x}-1}{1.695-1}, x \in[1,1.695] \\
1, x \in[1.695, \infty]
\end{array}\right.
$$

After that, the non-dimension data of the samples shown in Tables 5 and 6 are evaluated using the CTWF equations. The results of this operation are presented in Tables 7 and 8.

Table 7: Non-dimensioned data resulting from the leak with CTWF applied

\begin{tabular}{|c|c|c|c|c|c|c|c|c|}
\hline Sample 1 & $\boldsymbol{C}_{\mathbf{1}}$ & $\boldsymbol{C}_{\mathbf{2}}$ & $\boldsymbol{C}_{\mathbf{3}}$ & $\boldsymbol{C}_{\mathbf{4}}$ & $\boldsymbol{C}_{\mathbf{5}}$ & $\boldsymbol{C}_{\mathbf{6}}$ & $\boldsymbol{C}_{\mathbf{7}}$ & $\boldsymbol{C}_{\mathbf{8}}$ \\
\hline$f_{j}^{1}(x)$ & 0 & 0 & 0 & 0 & 0 & 0 & 0 & 0 \\
\hline$f_{j}^{2}(x)$ & 0 & 0.737 & 0 & 0 & 0 & 0 & 0 & 0 \\
\hline$f_{j}^{3}(x)$ & 1 & 0.201 & 1 & 1 & 1 & 1 & 1 & 1 \\
\hline Sample 2 & $\boldsymbol{C}_{\mathbf{1}}$ & $\boldsymbol{C}_{\mathbf{2}}$ & $\boldsymbol{C}_{\mathbf{3}}$ & $\boldsymbol{C}_{\mathbf{4}}$ & $\boldsymbol{C}_{\mathbf{5}}$ & $\boldsymbol{C}_{\mathbf{6}}$ & $\boldsymbol{C}_{\mathbf{7}}$ & $\boldsymbol{C}_{\mathbf{8}}$ \\
\hline$f_{j}^{1}(x)$ & 0 & 0.365 & 0 & 0 & 0 & 0 & 0 & 0 \\
\hline$f_{j}^{2}(x)$ & 0 & 0.634 & 0 & 0 & 0 & 0 & 0 & 0 \\
\hline$f_{j}^{3}(x)$ & 1 & 0 & 1 & 1 & 1 & 1 & 1 & 1 \\
\hline Sample 3 & $\boldsymbol{C}_{\mathbf{1}}$ & $\boldsymbol{C}_{\mathbf{2}}$ & $\boldsymbol{C}_{\mathbf{3}}$ & $\boldsymbol{C}_{\mathbf{4}}$ & $\boldsymbol{C}_{\mathbf{5}}$ & $\boldsymbol{C}_{\mathbf{6}}$ & $\boldsymbol{C}_{\mathbf{7}}$ & $\boldsymbol{C}_{\mathbf{8}}$ \\
\hline$f_{j}^{1}(x)$ & 1 & 0.857 & 0 & 1 & 0 & 0 & 0 & 0 \\
\hline$f_{j}^{2}(x)$ & 0 & 0.142 & 0 & 0 & 0.074 & 0 & 0 & 0 \\
\hline$f_{j}^{3}(x)$ & 0 & 0 & 1 & 0 & 0 & 1 & 0 & 1 \\
\hline Sample 4 & $\boldsymbol{C}_{\mathbf{1}}$ & $\boldsymbol{C}_{\mathbf{2}}$ & $\boldsymbol{C}_{\mathbf{3}}$ & $\boldsymbol{C}_{\mathbf{4}}$ & $\boldsymbol{C}_{\mathbf{5}}$ & $\boldsymbol{C}_{\mathbf{6}}$ & $\boldsymbol{C}_{\mathbf{7}}$ & $\boldsymbol{C}_{\mathbf{8}}$ \\
\hline$f_{j}^{1}(x)$ & 1 & 0.857 & 0 & 1 & 1 & 0 & 0 & 0 \\
\hline$f_{j}^{2}(x)$ & 0 & 0.142 & 0 & 0 & 1.09 & 0 & 0 & 0 \\
\hline$f_{j}^{3}(x)$ & 0 & 0 & 1 & 0 & 0 & 1 & 0 & 1 \\
\hline
\end{tabular}

Table 8: Non-dimensioned data resulting after the leak with CTWF applied

\begin{tabular}{|c|c|c|c|c|c|c|c|c|}
\hline Sample 1 & $\boldsymbol{C}_{\mathbf{1}}$ & $\boldsymbol{C}_{\mathbf{2}}$ & $\boldsymbol{C}_{\mathbf{3}}$ & $\boldsymbol{C}_{\mathbf{4}}$ & $\boldsymbol{C}_{\mathbf{5}}$ & $\boldsymbol{C}_{\mathbf{6}}$ & $\boldsymbol{C}_{\mathbf{7}}$ & $\boldsymbol{C}_{\mathbf{8}}$ \\
\hline$f_{j}^{1}(x)$ & 0 & 0 & 0 & 0 & 0 & 0 & 0 & 0 \\
\hline$f_{j}^{2}(x)$ & 0 & 0 & 0 & 0 & 0 & 0 & 0 & 0 \\
\hline$f_{j}^{3}(x)$ & 1 & 1 & 1 & 1 & 1 & 1 & 1 & 1 \\
\hline Sample 2 & $\boldsymbol{C}_{\mathbf{1}}$ & $\boldsymbol{C}_{\mathbf{2}}$ & $\boldsymbol{C}_{\mathbf{3}}$ & $\boldsymbol{C}_{\mathbf{4}}$ & $\boldsymbol{C}_{\mathbf{5}}$ & $\boldsymbol{C}_{\mathbf{6}}$ & $\boldsymbol{C}_{\mathbf{7}}$ & $\boldsymbol{C}_{\mathbf{8}}$ \\
\hline$f_{j}^{1}(x)$ & 0 & 0.422 & 0 & 0 & 0 & 0 & 0 & 0 \\
\hline$f_{j}^{2}(x)$ & 0 & 0.577 & 0 & 0.96 & 0 & 0 & 0 & 0 \\
\hline$f_{j}^{3}(x)$ & 1 & 0 & 1 & 0 & 1 & 1 & 1 & 1 \\
\hline Sample 3 & $\boldsymbol{C}_{\mathbf{1}}$ & $\boldsymbol{C}_{\mathbf{2}}$ & $\boldsymbol{C}_{\mathbf{3}}$ & $\boldsymbol{C}_{\mathbf{4}}$ & $\boldsymbol{C}_{\mathbf{5}}$ & $\boldsymbol{C}_{\mathbf{6}}$ & $\boldsymbol{C}_{\mathbf{7}}$ & $\boldsymbol{C}_{\mathbf{8}}$ \\
\hline$f_{j}^{1}(x)$ & 1 & 1 & 0 & 1 & 0 & 0 & 0 & 0 \\
\hline$f_{j}^{2}(x)$ & 0 & 0 & 0 & 0 & 0.09 & 0 & 0 & 0.71 \\
\hline$f_{j}^{3}(x)$ & 0 & 0 & 1 & 0 & 0 & 1 & 0 & 1 \\
\hline Sample 4 & $\boldsymbol{C}_{\mathbf{1}}$ & $\boldsymbol{C}_{\mathbf{2}}$ & $\boldsymbol{C}_{\mathbf{3}}$ & $\boldsymbol{C}_{\mathbf{4}}$ & $\boldsymbol{C}_{\mathbf{5}}$ & $\boldsymbol{C}_{\mathbf{6}}$ & $\boldsymbol{C}_{\mathbf{7}}$ & $\boldsymbol{C}_{\mathbf{8}}$ \\
\hline$f_{j}^{1}(x)$ & 1 & 0.857 & 0 & 1 & 1 & 0 & 0 & 1 \\
\hline$f_{j}^{2}(x)$ & 0 & 0.142 & 0 & 0 & 0 & 0 & 0 & 0.04 \\
\hline$f_{j}^{3}(x)$ & 0 & 0 & 1 & 0 & 0 & 1 & 0 & 0 \\
\hline
\end{tabular}

\section{Third Step}

The clustering weights were calculated using (4). The values of Table 4 were then replaced in this equation. The weights of each parameter proposed by MINAM obtained are shown in Table 9.

Table 9: Parameters Weights

\begin{tabular}{|l|c|c|c|c|}
\hline \multirow{2}{*}{ Code } & \multirow{2}{*}{ Parameter } & \multicolumn{3}{|c|}{ Class } \\
\cline { 3 - 5 } & & $\boldsymbol{A}_{\mathbf{1}}$ & $\boldsymbol{A}_{\mathbf{2}}$ & $\boldsymbol{A}_{\mathbf{3}}$ \\
\hline $\boldsymbol{C}_{\mathbf{1}}$ & $\mathbf{A l}$ & 0.117 & 0.108 & 0.118 \\
\hline $\boldsymbol{C}_{\mathbf{2}}$ & $\mathbf{A s}$ & 0.286 & 0.108 & 0.106 \\
\hline $\boldsymbol{C}_{\mathbf{3}}$ & $\mathbf{C d}$ & 0.072 & 0.129 & 0.120 \\
\hline $\boldsymbol{C}_{\mathbf{4}}$ & $\mathbf{C u}$ & 0.072 & 0.108 & 0.133 \\
\hline $\boldsymbol{C}_{\mathbf{5}}$ & $\mathbf{F e}$ & 0.250 & 0.226 & 0.084 \\
\hline $\boldsymbol{C}_{\mathbf{6}}$ & $\mathbf{M n}$ & 0.048 & 0.108 & 0.160 \\
\hline $\boldsymbol{C}_{\mathbf{7}}$ & $\mathbf{P b}$ & 0.107 & 0.108 & 0.120 \\
\hline $\boldsymbol{C}_{\mathbf{8}}$ & $\mathbf{Z n}$ & 0.048 & 0.108 & 0.160 \\
\hline
\end{tabular}

\section{Fourth Step}

The clustering coefficients $\sigma_{i}^{k}$ were obtained using the values resulted of the CTWF (from Tables 7 and 8) and the clustering weight used in the previous step is shown in Table 9. Therefore, and considering the data collected, the results of this coefficients are observed in Table 10.

Table 10: Clustering Coefficients Data

\begin{tabular}{|c|c|c|c|}
\hline \multirow{2}{*}{$\begin{array}{c}\text { Monitoring } \\
\text { point }\end{array}$} & \multicolumn{3}{|c|}{ Categories } \\
\cline { 2 - 4 } & $\boldsymbol{A}_{\mathbf{1}}$ & $\boldsymbol{A}_{\mathbf{2}}$ & $\boldsymbol{A}_{\mathbf{3}}$ \\
\hline Sample 1 & 0 & 0.079 & 0.915 \\
\hline Sample 2 & 0.104 & 0.068 & 0.894 \\
\hline Sample 3 & 0.434 & 0.241 & 0.439 \\
\hline Sample 4 & 0.685 & 0.261 & 0.439 \\
\hline & \multicolumn{3}{|c|}{ Resulting after the leak } \\
\hline Sample 1 & 0 & 0 & 1 \\
\hline Sample 2 & 0.121 & 0.165 & 0.760 \\
\hline Sample 3 & 0.475 & 0.097 & 0.439 \\
\hline Sample 4 & 0.732 & 0.020 & 0.279 \\
\hline
\end{tabular}

\section{E. Fifth Step}

Finally, using the $\max \left(\sigma_{i}^{k}\right)$, meaning the higher grey coefficient of each sample, it is decided of which category belong each one of the samples considered. The relation is expressed in Table 11.

Table 11: Maximum Clustering Coefficients

\begin{tabular}{|l|c|c|}
\hline Monitoring Point & $\max \boldsymbol{\sigma}_{\boldsymbol{i}}^{\boldsymbol{k}}$ & Category \\
\hline \multicolumn{3}{|c|}{ Resulting from the leak } \\
\hline Sample 1 & 0.915 & A3 \\
\hline Sample 2 & 0.894 & A3 \\
\hline Sample 3 & 0.439 & A3 \\
\hline Sample 4 & 0.685 & A1 \\
\hline \multicolumn{3}{|c|}{ Resulting after the leak } \\
\hline Sample 1 & 1.000 & A3 \\
\hline Sample 2 & 0.760 & A3 \\
\hline Sample 3 & 0.475 & A1 \\
\hline Sample 4 & 0.732 & A1 \\
\hline
\end{tabular}




\section{RESULTS AND DISCUSSIONS}

After the methodology has been developed, the samples will be classified, and the results are shown in Tables 12 and 13.

Table 12: Results according to the data obtained from the leak

\begin{tabular}{|c|c|}
\hline Monitoring Point & Category \\
\hline Sample 1 & $A_{3}$ \\
\hline Sample 2 & $A_{3}$ \\
\hline Sample 3 & $A_{3}$ \\
\hline Sample 4 & $A_{1}$ \\
\hline
\end{tabular}

Table 13: Results according to the data obtained after the leak

\begin{tabular}{|c|c|}
\hline Monitoring Point & Category \\
\hline Sample 1 & $A_{3}$ \\
\hline Sample 2 & $A_{3}$ \\
\hline Sample 3 & $A_{1}$ \\
\hline Sample 4 & $A_{1}$ \\
\hline
\end{tabular}

\subsection{About the Case Study}

From the case of study, it can be seen in Table 12 that, because of the leak, the monitoring points where it has been taken samples 1, 2 and 3 had a higher level of contamination as those points were classified as A3 category (water that might be purified by advanced treatment). However, it has been detected that the sample 4 presented a good water quality which means that it could be purified by disinfection. In other words, the point 4 has not been highly impacted by the leak of residual water. This must be due to the distance from the point 4 and the leak.

On the other hand, in Table 13, it can be appreciated that the monitoring points 1 and 2 were classified as category A3 yet, even after the leak has been locked. However, the monitoring point 3 has changed the category after the leak got locked, which means that the monitoring point 3 changed to the category A1, demonstrating a quantitative improvement. That means that the blocking of the leak had a good impact in the point 3 , but the point 1 and 2 were not impacted by the obstruction.

\subsection{About the Methodology}

Finally, the methodology that it has been developed, Grey clustering, considers the uncertainty in their analysis[6], which have made possible for this study to be performed. It would be more efficient to make a classification than other classic process of multi-criteria-analysis like Delphi[26] or analytic hierarchy process (AHP)[27], [28], as these processes do not consider the uncertainty in their analysis[29] However, some real problems often come out with dynamic characteristics that changes with environment, and then decision-making becomes a dynamic evolutionary process [30].

\section{CONCLUSIONS}

From the results obtained it was identified that the degree of contamination at the sampling points depended on the proximity to the mining operation where the river effluent is responsible for the transport of heavy metals. In the regards of water purification, points 1 and 2 required advanced treatment, which can be a tough process to performsince there are previous damages in the nearby population, so the treatment process must be efficient for a better social appreciation and impacts. With the results obtained, we conclude that there is a direct relationship between the mining operation and water contamination but can be either positive or negative according to the engagement of the agents involved and their conflict management.

The grey clustering method was used effectively to provide a more precise theoretical basis for water quality management; in this document the areas to be prioritized are identified and different weight coefficients are determined for each parameter for importance using the averagedata, step that makes the evaluation more complete,leading to an easy application method based on basic information which provides a specific idea.

Finally, with the evaluation of the water quality of Taxco River, the present expects to be a reference to the process needed to purify water for future studies. Therefore, in future works, it is recommended to develop this method with the values of the standard parameters given by the Norma Official Mexicana NOM-001-SEMARNAT-1996 and to take advantage of the method as grey clustering could be applied with other methods to make comparison and reduce uncertainty.

\section{REFERENCES}

1. S. Liu and Y. Lin, Introduction to grey systems theory, vol. 68. 2010. https://doi.org/10.1007/978-3-642-16158-2_1

2. A. Delgado, D. Vriclizar, and E. Medina, Artificial intelligence model based on grey systems to assess water quality from Santa river watershed, in 2017 Electronic Congress (E-CON UNI), 2017, pp. 1-4.

3. A. Delgado and I. Romero, Social impact assessment on a hydrocarbon proyect using triangular whitenization weight functions, in 2016 IEEE Congreso Argentino de Ciencias de la Informática y Desarrollos de Investigación (CACIDI), 2016, pp. 1-6. https://doi.org/10.1109/CACIDI.2016.7785998

4. A. Delgado, C. Carbajal, H. Reyes, and I. Romero, Social Impact Assessment on a Mining Project in Peru Using the Grey Clustering Method and the Entropy-Weight Method, Commun. Comput. Inf. Sci., vol. 1096 CCIS, pp. 116-128, 2019.

5. A. Delgado and A. Aguirre, Air Quality level Assessment through the Grey Clustering Analysis on Lima, Peru.

6. L. Zhang, F. Wu, and P. Jia, Grey Evaluation Model Based on Reformative Triangular Whitenization Weight Function and Its Application in Water Rights 
Allocation System, Open Cybern. Syst. J., vol. 7, pp. 1-10, 2013.

7. R. Temino Boes, R. Romero Lopez, S. P. Ibarra Zavaleta, and I. Romero, Using grey clustering to evaluate nitrogen pollution in estuaries with limited data, Sci. Total Envinronment, vol. 722, p. 137964, 2020. https://doi.org/10.1016/j.scitotenv.2020.137964

8. M. Méndez and M. A. Armienta, Distribución de Fe, $\mathrm{Zn}, \mathrm{Pb}, \mathrm{Cu}, \mathrm{Cd}$ y As originada por residuos mineros y aguas residuales en un transecto del Río Taxco en Guerrero, México, Rev. Mex. Ciencias Geol., vol. 29, no. 2, pp. 450-462, 2012.

9. M. A. Armienta et al., Environmental behaviour of metals from tailings in shallow rivers: Taxco, central Mexico, Appl. Earth Sci. Trans. Inst. Min. Metall. Sect. B, vol. 113, no. 1, pp. 76-82, 2004.

10. S. de M. A. y R. N. (SEMARNAT), Norma Oficial Mexicana NOM-001-SEMARNAT-1996, Que establece los límites máximos permisibles de contaminantes en las descargas de agua residuales en aguas y bienes nacionales. Diario Oficial de la Federación. 1997.

11. S. de S. y A. (SSA), Modificación a la Norma Oficial Mexicana NOM-127-SSA1-1994, salud ambiental, Agua para uso y consumo humano, Límites permisibles de calidad $y$ tratamientos a que debe someterse el agua para su potabilización. 2000.

12. W. H. O. (WHO), Guidelines for drinking water quality. Vol1, Recomendations: Geneva, Word Health Organization. 2004, p. 515.

13. F. Arcega-Cabrera, M. A. Armienta, L. W. Daesslé, S. E. Castillo-Blum, O. Talavera, and A. Dótor, Variations of $\mathrm{Pb}$ in a mine-impacted tropical river, Taxco, Mexico: use of geochemical, isotopic and statistical tools, Appl. Geochemistry, vol. 24, no. 1, pp. 162-171, 2009.

14. F. Li and F. Y. Dong, Grey clustering evaluation on regional tourism economy development in China, in Proceedings of IEEE International Conference on Grey Systems and Intelligent Services, GSIS, 2013, pp. 274-279.

15. X. Miao, Grey clustering evaluation for groundwater quality, in 2011 International Conference on Remote Sensing, Environment and Transportation Engineering, RSETE 2011 - Proceedings, 2011, pp. 5011-5014.

16. W. Cui and S. Jin, Research of constructing method of manufacturing cells based on grey clustering, in Proceedings - 2011 8th International Conference on Fuzzy Systems and Knowledge Discovery, FSKD 2011, 2011, vol. 1, pp. 357-360.

17. G. $\mathrm{Xu}$ and $\mathrm{P}$. Guo, The design of an application environment identification system of aerospace components based on the grey clustering analysis, in Proceedings of IEEE International Conference on Grey Systems and Intelligent Services, GSIS, 2013, pp. 280-283.

18. M. Xiaokun, Grey clustering evaluation for urban road traffic environment quality, in 2011 International Conference on E-Business and E-Government, ICEE2011 - Proceedings, 2011, pp. 6048-6051. https://doi.org/10.1109/ICEBEG.2011.5884495
19. C. Zhu and N. Li, Study on Grey Clustering Model of Indoor Air Quality Indicators, Procedia Eng., vol. 205, pp. 2815-2822, 2017.

20. K. Liu, S. Xiaoliub, T. Zhongfu, and G. Wenyan, Grey Clustering Analysis Method for Overseas Energy Project Investment Risk Decision, Syst. Eng. Procedia, vol. 3, pp. 55-62, 2012.

21. X. Naiming, B. Su, and C. Nanlei, Construction mechanism of whitenization weight function and its application in grey clustering evaluation, J. Syst. Eng. Electron., vol. 30, pp. 121-131, 2019.

22. C. Zhu and Q. Liu, Evaluation of water quality using grey clustering, in Proceedings - 2009 2nd International Workshop on Knowledge Discovery and Data Mining, WKKD 2009, 2009, pp. 803-805.

23. S. A. Alaniz-Álvarez, A. F. Nieto-Samaniego, D. J. Morán-Zenteno, and L. Alba-Aldave, Rhyolitic volcanism in extension zone associated with strike-slip tectonics in the Taxco region, southern Mexico, J. Volcanol. Geotherm. Res., vol. 118, no. 1-2, pp. 1-14, 2002.

24. F. M. Romero, L. Núñez, M. E. Gutiérrez, M. A. Armienta, and A. E. Ceniceros-Gómez, Evaluation of the potential of indigenous calcareous shale for neutralization and removal of arsenic and heavy metals from acid mine drainage in the Taxco mining area, Mexico, Arch. Environ. Contam. Toxicol., vol. 60, no. 2, pp. 191-203, 2011. https://doi.org/10.1007/s00244-010-9544-z

25. E. Peruano and P. Ejecutivo, 569076 Normas Legales, pp. 569076-569082, 2015.

26. V. Campos Climent, A. Melián Navarro, and J. R. Sanchis Palacio, El método Delphi como técnica de diagnóstico estratégico. Estudio empírico aplicado a las empresas de inserción en España, Rev. Eur. Dir. y Econ. la Empres., vol. 23, no. 2, pp. 72-81, Apr. 2014.

27. T. L. Saaty and L. G. Vargas, Modeling behavior in competition: The analytic hierarchy process, Appl. Math. Comput., vol. 16, no. 1, pp. 49-92, Jan. 1985.

28. A. Sadeghi, M.; Ameli, An AHP decision making model for optimal allocation of energy subsidy among socio-economic subsectors in Iran, Energy Policy, vol. 45, pp. 24-32, 2012.

29. A. Baykasołlu and I. Gölcük, Development of a novel multiple-attribute decision making model via fuzzy cognitive maps and hierarchical fuzzy TOPSIS, Inf. Sci. (Ny)., vol. 301, pp. 75-98, Apr. 2015.

30. Y. Liu and R.-S. Zhang, A three-way grey incidence clustering approach with changing decision objects, Comput. Ind. Eng., vol. 137, p. 106087, 2019. https://doi.org/10.1016/j.cie.2019.106087 